\title{
The Effect of Gavage Feeding on the Mechanics of the Lung, Chest Wall, and Diaphragm of Preterm Infants
}

\author{
GREGORY P. HELDT \\ Department of Pediatrics, University of California Medical Center, San Diego, and University of California, \\ San Francisco, California
}

\begin{abstract}
Preterm infants when given bolus nasogastric (gavage) feedings have well-characterized decreases in arterial partial pressure of oxygen, increases in arterial partial pressure of carbon dioxide, a tendency to have apnea, and are reported to have no change in the mechanics of breathing. The purpose of this study was to assess the function of the lungs, chest wall, and diaphragm in preterm infants without lung disease before and after gavage feeding. Lung mechanics were measured with a pneumotachograph and esophageal balloon, and the mechanics of the chest wall and diaphragm were assessed by inductance plethysmography and measurement of transdiaphragmatic pressure. After feeding, there was a significant decrease in dynamic lung compliance and increase in the minute ventilation $(p<0.05)$. The work performed on the lungs was unchanged. The chest wall became more stable, with a significant decrease in its dynamic compliance $(p<0.05)$. The diaphragmatic volume displacement, expressed as a percentage of the minute ventilation, was unchanged. The diaphragmatic work increased significantly $(p<0.05)$, and was greater than four times the work performed on the lungs. These results are consistent with previous reports of a decrease in functional residual capacity after feeding. The mechanical stability of the chest wall may have been improved by an increase in the area of apposition of the diaphragm to it, or by an increase in the central drive to breathing after feeding. The increment in diaphragmatic work after feeding, being nearly as large as the absolute amount of work performed on the lungs, may be enough to cause muscular fatigue and resultant apnea noted in some preterm infants after gavage feeding. (Pediatr Res 24: 5558,1988 )
\end{abstract}

\section{Abbreviation}

FRC, functional residual capacity

A major goal of the care of preterm infants is to provide adequate nutrition with enteral feeds as soon as possible after birth. Feeding small preterm infants has been associated with reduction of arterial partial pressure of oxygen, an increased incidence of apnea and episodes of cyanosis (1), and a reduced arterial $\mathrm{pH}(2)$. Studies of the mechanics of breathing in healthy term (3) and preterm infants demonstrated that the work of breathing was unchanged, and that the dynamic lung compliance was unchanged (4) or increased (5), a paradoxical

Received November 25, 1987; accepted March 2, 1988

Correspondence, Gregory P. Heldt, UCSD Medical Center, H-638-A, 225 W. Dickinson Street, San Diego, CA 92103-1990.

Supported in part by NHLBI SCOR HL 27356 and ALA 57002. finding in view of the postprandial respiratory instability commonly seen in preterm infants. This is especially true because gavage feeding has been shown to be associated with a reduction in FRC in healthy preterm infants (6). Studies of preterm infants who required supplemental oxygen showed no change in their compliance after feeding, although their baseline compliance values were lower than normal (5).

The aim of this study was to determine the effect of gavage feeding on the mechanics of the lungs, chest wall, and diaphragm of small preterm infants. It was hypothesized that the changes in the dynamics of the chest wall and the diaphragm after feeding may be more important than the dynamics of the lungs in the infants. We have recently demonstrated that the volume displacement of the diaphragm and the pressure-volume work performed by the diaphragm may be greater than the pulmonary ventilation and pressurevolume work performed on the lungs $(7,8)$. In this study, these methods were applied to quantify the effect of abdominal loading due to gavage feeding on the function of the lungs, chest wall, and diaphragm.

\section{METHODS}

Studies were performed in 13 preterm infants. Their birth weights ranged from 680 to $1730 \mathrm{~g}$, and their weights at the time of study ranged from 870 to $1740 \mathrm{~g}$ (mean $1280 \pm 210 \mathrm{~g}$ ). Studies were performed between 29 and 34 wk of postconceptional age, corresponding to 2 to $4 \mathrm{wk}$ of chronological age. All infants were in a stable pattern of weight gain and were being fed every $2 \mathrm{~h}$ by nasogastric tube. None required supplemental oxygen. All had visible paradoxical chest wall movement whether sleeping or awake. Studies were coordinated with routine feedings and did not interfere with the infants' care. Informed consent was obtained from the parents before enrollment in the study.

Changes in the chest wall volume and diaphragmatic volume displacement were estimated with a Respitrace inductance plethysmograph (9). The bands of the plethysmograph were placed around the chest and abdomen centered at the level of the nipples and umbilicus, respectively. Airway flow was measured with a Fleisch no. 00 pneumotachograph attached to a face mask (Bennett, Inc., dead space approximately $1.9 \mathrm{ml}$ ). Esophageal and gastric pressures were measured with a modified two lumen feeding catheter system (National Catheter Co.). Esophageal pressure was measured with a pressure transducer (Validyne MP45) connected by one lumen to a $1 \times 3 \mathrm{~cm}$, thin-walled latex balloon located $5 \mathrm{~cm}$ from the tip of the catheter. Gastric pressure was measured with a pressure transducer (Statham PM-131) connected to a side hole at the tip of the catheter by the other lumen filled with water. The pressure-volume characteristics of the esophageal balloon system were determined and the flat part of the pressure-volume curve was shown to be at a volume of 
$0.6 \mathrm{ml}(10)$. Measurements were made with the balloon filled with this volume of air.

Airway pressure was measured with a pressure transducer (Validyne MP-45) attached to the proximal port of the pneumotachograph. The amplitude-frequency response of the inductance plethysmograph was flat to $13 \mathrm{~Hz}$ and that of the pressure and the flow measurement systems was flat to $15 \mathrm{~Hz}$ (7). The signals from the inductance plethysmograph and the pressure and flow transducers were digitized 60 times/s using a microcomputer and data acquisition system (11). The pressure transducers were calibrated with a water manometer and the pneumotachograph was calibrated with a rotameter. The calibration factors were calculated by the microcomputer and stored with patient information in a file on a floppy diskette for later use in the calculation programs. During the following procedures, the signals were graphically displayed on a video monitor.

The infants were studied in the supine position in their isolettes. Their heart and respiratory rates were monitored during the studies. The bands of the inductance plethysmograph were fixed in place with Velcro strips. The gastric lumen of the catheter was flushed with water, and the volume of the esophageal balloon was adjusted. The catheter was then passed through the mouth and into the infant's stomach while the esophageal and gastric pressures were monitored. The deflections of the esophageal and gastric pressures on the video monitor were made equal during the calibration procedure so that after the catheter was passed into the stomach, the two signals could be superimposed by adjusting the zero offset of the gastric pressure measurement system. This was performed as a check of the frequency response of both systems and to establish a common baseline for subsequent pressure measurements. The catheter was then withdrawn until the esophageal pressure swings were observed to be maximal with inspiration.

When infants were observed to be in quiet sleep (as determined by a regular pattern of breathing and the absence of body movements) the gain and zero offset of the inductance plethysmograph channels were adjusted to give an adequate deflection on the video monitor with the instrument in the AC-coupled mode. Subsequent recordings were made with the instrument in the DC-coupled mode. A preliminary check on the quality of the volume partitioning was made by placing a face mask and pneumotachograph on the infant's face and gathering $5 \mathrm{~s}$ of data from the inductance plethysmograph and the airway flow. A multiple linear regression was used to fit the changes in the chest wall and abdominal signals to the changes in the integrated airway flow (7). The position of the bands were adjusted so that the $r$ value of the multiple linear regression relationship was more than 0.95 by this preliminary check. The gastric catheter was flushed in the water and the position of the esophageal balloon was validated by airway occlusion (12). Transdiaphragmatic pressure was calculated as the difference in the esophageal and gastric pressures and was used to calculate the pressurevolume work of the diaphragm (7). Transpulmonary pressure was calculated as the difference between the airway pressure and esophageal pressure.

The face mask was then placed on the infant's face and an 8 to 10-min data collection was started. The neck of the infant was maintained in a neutral position and the flow signal was observed to be sure that the face mask did not cause upper airway obstruction. During the data collection, the airway was occluded several times a minute by placing a finger over the opening of the mask at end expiration for one or two respiratory efforts to check the volume partitioning (see below).

Typical signals from the chest and abdomen of the inductance plethysmograph, the airflow from the pneumotachograph, and esophageal, gastric, and airway pressures are shown in Figure 1. The chest wall moved paradoxically during inspiration and above its resting volume during expiration. Esophageal and gastric pressures were of similar magnitudes and out of phase. During airway occlusion, the chest and abdomen moved reciprocally which was used as a subsequent check on the volume partitioning. The airway pressure change was not significantly different than the esophageal pressure change, indicating proper esophageal balloon positioning. Linear regression comparisons of the airway and esophageal pressures during occlusion showed an average slope of $0.97 \pm 0.04$ for all breaths used in calculations.

After the data collection, the infant was fed the usual amount of formula $(10-15 \mathrm{ml} / \mathrm{kg})$ by injecting it into the stomach over 1-2 min, observing routine nursing procedure. After the feeding, the position of the esophageal balloon was checked by airway occlusion and the gastric lumen of the catheter was flushed with water. The data collection was repeated 5-15 min after the feeding when the infant was again observed to be in quiet sleep. The infants usually slept through the data collections and feedings. If there was significant arousal or movement during feeding, the preliminary volume partitioning check was repeated before the second data collection. The data collection was interrupted if body movement, swallowing artifact on the esophageal pressure signal, or a change in sleep state was observed, and resumed when the infants were again in quiet sleep. The multiple linear regression calibration was checked for each breath using airway occlusion method both before and after feeding.

Data analysis. After the data collection, the data were graphically displayed on the video monitor as a function of time. A cursor was moved on the screen to choose the beginning, middle, and end of each breath to be analyzed using the pneumotachograph signal. The beginning and end of an airway occlusion performed within two respiratory efforts of the breath chosen for analysis were chosen to check the volume partitioning.

Volume partitioning was then performed using a multiple linear regression analysis to relate the changes in chest wall and abdominal volumes during each breath to the change in lung volume calculated by numerical integration of the pneumotachograph signal. The quality of the volume partitioning was then checked by correlating the changes in chest wall volume to the changes in abdominal volume during airway occlusion. During airway occlusion, the changes in the chest wall and abdominal volumes should be reciprocal because there is no appreciable change in lung volume. If the calibration coefficients for the

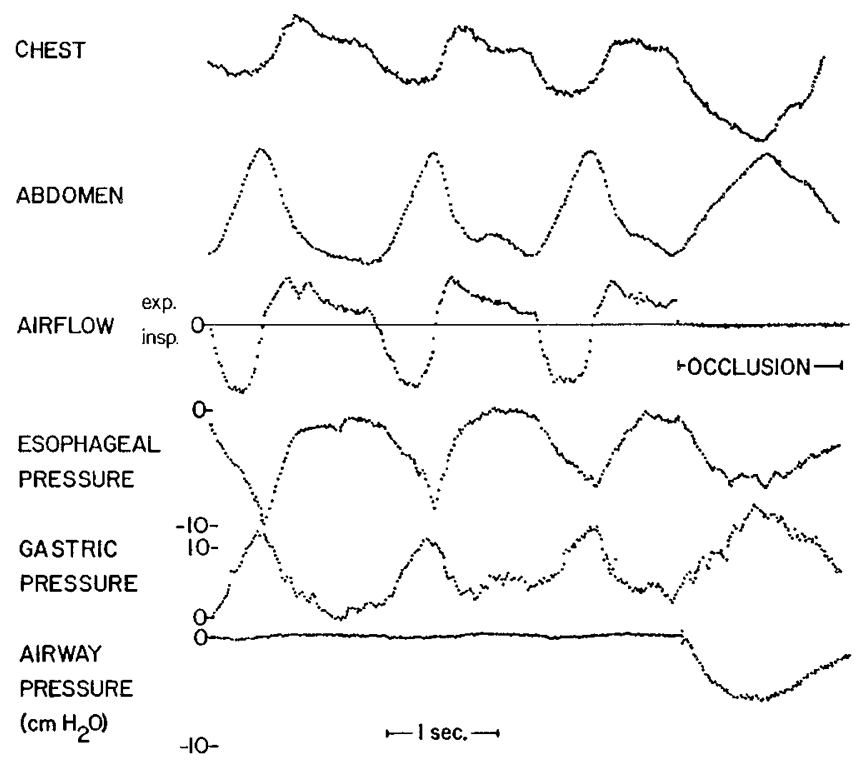

Fig. 1. Chest and abdomen signals from the inductance plethysmograph, air flow measured with a pneumotachograph, and esophageal, gastric, and airway pressures in a typical study. Three unoccluded breaths show consistent paradoxical chest wall movement. During airway occlusion, chest and abdomen move reciprocally, providing a check for the volume partitioning calibration. Esophageal balloon placement was also validated by occlusion. 
chest wall and abdomen derived by the multiple linear regression were significantly different than those derived by the airway occlusion check, the data were discarded and the data from the next breath and its associated airway occlusion were tested and calculated. The coefficients of variability for the chest and abdominal calibration coefficients were 8.9 and $7.1 \%$, respectively.

The mechanics of the lungs were then calculated. Dynamic lung compliance was calculated by dividing the tidal volume by the change in transpulmonary pressure at points of zero flow. The total pulmonary resistance was calculated at midtidal volume (13). The work performed on the lungs was calculated as the integral of the product of the change in transpulmonary pressure and the instantaneous change in the lung volume during inspiration.

The stability of the chest wall was assessed by calculation of its dynamic compliance (Fig. 2). During inspiration, there was paradoxical, inward chest wall movement with decreasing (referenced to atmospheric) transthoracic pressure. The dynamic compliance of the chest wall was calculated by dividing the volume change of the calibrated chest wall signal at points of zero flow of the chest wall signal by the change in transthoracic pressure at those points (8).

The dynamics of the diaphragm were calculated as previously described (7). The minute volume displacement of the diaphragm was calculated as the change in the calibrated abdominal volume during inspiration divided by the period of the breath in minutes. The inspiratory work of the diaphragm was calculated as the integral of the product of the change in transdiaphragmatic

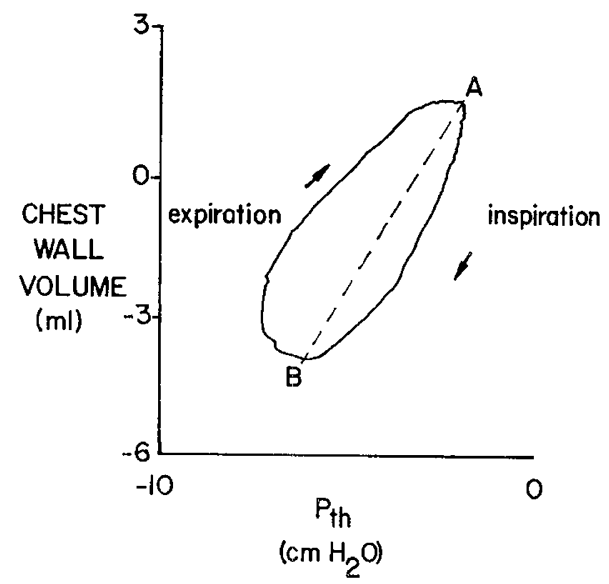

Fig. 2. Relationship of chest wall volume and transthoracic pressure. During inspiration there is paradoxical chest wall movement. Dynamic compliance is the slope of line $A B$, drawn between points of zero flow for the chest wall. Points $A$ and $B$ do not correspond to points of zero flow for the lungs. pressure and the instantaneous change in abdominal volume (diaphragmatic volume displacement) during inspiration. The minute volume displacement of the diaphragm was expressed as a percentage of the pulmonary ventilation and the work of the diaphragm was normalized for body weight and expressed in U/ min. Mean values for these parameters were calculated for 7 to 15 breaths in each study.

We compared the change after feeding of the average values of the dynamic lung and chest wall compliances, total pulmonary resistance, minute ventilation, work performed on the lungs, and diaphragmatic volume displacement by paired student's $t$ test.

\section{RESULTS}

The mechanics of the lungs, chest wall, and diaphragm are shown in Table 1 . The dynamic lung compliance decreased significantly $(p<0.05)$ and the minute ventilation significantly increased $(p<0.05)$. The work performed on the lungs was increased; however, this was not consistent between breaths in each infant and was not statistically significant.

Paradoxical chest wall movement was observed consistently in all infants. The chest wall became stiffer with a significant decrease in dynamic compliance $(p<0.05)$. The coefficient of variability of this parameter averaged $12.2 \%$.

The volume displacement of the diaphragm increased after feeding, but was unchanged when expressed as a percentage of the minute pulmonary ventilation. The pressure-volume work of the diaphragm increased significantly $(p<0.05)$, also in proportion to the increase in the minute pulmonary ventilation $(118 \%)$. After feeding, the mean intragastric pressure increased $1.2 \mathrm{~cm} \mathrm{H}_{2} \mathrm{O}$ which was not statistically significant due to large variability between infants. There was no significant change in end-expiratory esophageal pressure or in the total pulmonary resistance after feeding. The changes in these parameters were not related to the infant's size or postconceptional age, although the MVDD and DW tended to decrease with study weight.

\section{DISCUSSION}

The dynamic lung compliance of our infants in the preprandial study $\left(3.62 \mathrm{ml} \times \mathrm{cm} \mathrm{H}_{2} \mathrm{O}^{-1}\right)$ was intermediate between values reported by Feather and Russell (5) for larger preterm infants who were healthy or who required supplemental oxygen (4.4 and $1.1 \mathrm{ml} \times \mathrm{cm} \mathrm{H}_{2} \mathrm{O}^{-1}$, respectively). In their study, healthy preterm infants were shown to have an increase in the compliance after feeding: the smaller infants in the present study, however, had a decrease in compliance. The decreased average compliance observed was more consistent with the decrease in FRC after feeding reported by Pitcher-Wilmott et al. (6). The infants in our study had an increase in minute ventilation and work performed on the lungs after feeding similar to that reported by Bakulesh et al. (4), when these parameters were corrected for body weight.

Table 1. Changes in mechanics of lungs, chest wall, and diaphragm with gavage feeding (mean \pm SEM)

\begin{tabular}{|c|c|c|c|c|}
\hline & Prefeed & Postfeed & Average change & $p$ \\
\hline $\begin{array}{l}\text { Dynamic lung compliance } \\
\left(\mathrm{ml} \times \mathrm{cm} \mathrm{H} \mathrm{H}_{2} \mathrm{O}^{-1}\right)\end{array}$ & $\begin{array}{r}3.62 \\
\pm 0.24\end{array}$ & $\begin{array}{r}2.96 \\
\pm 0.49\end{array}$ & $\begin{array}{l}-0.30 \\
\pm 0.13\end{array}$ & $<0.05$ \\
\hline $\begin{array}{l}\text { Minute ventilation }(\mathrm{ml} \times \\
\left.\min ^{-1} \times \mathrm{kg}^{-1}\right)\end{array}$ & $\begin{array}{r}355 \\
\pm 42\end{array}$ & $\begin{array}{r}418 \\
\pm 58\end{array}$ & $\begin{array}{l}+65 \\
\pm 26\end{array}$ & $<0.05$ \\
\hline $\begin{array}{l}\text { Dynamic chest wall compliance } \\
\left(\mathrm{ml} \times \mathrm{cm} \mathrm{H}_{2} \mathrm{O}^{-1}\right)\end{array}$ & $\begin{array}{r}2.80 \\
\pm 0.30\end{array}$ & $\begin{array}{r}1.62 \\
\pm 0.28\end{array}$ & $\begin{array}{r}1.50 \\
\pm 0.54\end{array}$ & $<0.05$ \\
\hline $\begin{array}{l}\text { Work performed on lungs (g } \\
\left.\times \mathrm{cm} \mathrm{H}_{2} \mathrm{O} \times \min ^{-1} \times \mathrm{kg}^{-1}\right)\end{array}$ & $\begin{array}{r}794 \\
\pm 140\end{array}$ & $\begin{array}{r}885 \\
\pm 335\end{array}$ & $\begin{array}{r}+91 \\
\pm 298\end{array}$ & \\
\hline $\begin{array}{l}\text { Diaphragm vol. displacement } \\
\text { (\% of minute ventilation) }\end{array}$ & $\begin{array}{l}98 \\
\pm 9\end{array}$ & $\begin{array}{l}98 \\
\pm 8\end{array}$ & $\begin{array}{r}-7 \\
\pm 12\end{array}$ & \\
\hline $\begin{array}{l}\text { Diaphragmatic work }(\mathrm{g} \times \mathrm{cm} \\
\left.\mathrm{H}_{2} \mathrm{O} \times \mathrm{min}^{-1} \times \mathrm{kg}^{-1}\right)\end{array}$ & $\begin{array}{r}3232 \\
\pm 661\end{array}$ & $\begin{array}{r}3772 \\
\pm 963\end{array}$ & $\begin{array}{l}+982 \\
\pm 382\end{array}$ & $<0.05$ \\
\hline $\begin{array}{l}\text { Average intragastic pressure } \\
\left(\mathrm{cm} \mathrm{H}_{2} \mathrm{O}\right)\end{array}$ & $\begin{array}{r}4.2 \\
\pm 2.1\end{array}$ & $\begin{array}{r}5.4 \\
\pm 1.2\end{array}$ & $\begin{array}{r}1.2 \\
\pm 2.0\end{array}$ & \\
\hline
\end{tabular}


The chest wall had greater mechanical stability after feeding, as it had decreased paradoxical motion and significantly lower dynamic compliance. This may be explained in several ways. The increased metabolic rate observed in infants after feeding may present an increased central drive to respiration. This may be associated with increased intercostal muscle contraction or improved phasic intercostal contractions as infants were studied in quiet sleep.

The greater mechanical stability after feeding may also be explained in part by an increase in the area of apposition of the diaphragm to the chest wall. During inspiration, positive intraabdominal pressure is applied to the chest wall over the area of apposition of the diaphragm to the chest wall. This provides an outward force that helps to expand the chest wall. After feeding, if there is a decrease in the FRC (consistent with the decrease in the observed lung compliance), the area of apposition may be increased. Furthermore, after feeding, there was a slight increase in the intraabdominal (gastric) pressure. Thus, the load imposed by feeding may confer two advantages to the diaphragm: the area of apposition may have been enlarged and a slightly greater intraabdominal pressure may have been applied to the chest wall which increased its stability.

The dynamic chest wall compliance decreased and was considerably lower than reported "static" chest wall compliances. These two measurements reflect the stiffness of the chest wall over different ranges of chest wall volume: the dynamic chest wall compliance is measured at lower volumes than when it is passively inflated by applying positive pressure to the airway during the measurement of static compliance (14). Inasmuch as the chest wall is stiffer at lower volumes (15), the dynamic chest wall compliance is lower than the static compliance.

The work of the diaphragm increased in proportion to its volume displacement. We expected to see a larger increase in intraabdominal (gastric) pressure after feeding which would result in an increase in the diaphragmatic work out of proportion to the diaphragmatic volume displacement. The variable increase in the gastric pressure in these small infants was similar to that reported in larger preterm infants (16) and presented less of an abdominal load than anticipated. The increase in pressure-volume work in proportion to volume displacement also suggests that the pressure-volume efficiency of the diaphragm improved. This may be explained by the increased area of apposition. It may also have been due to a decrease in the radius of the curvature of the diaphragmatic dome caused by an increase in the hydrostatic load imposed by the abdominal contents after feeding. The smaller radius would allow the diaphragm to develop greater transdiaphragmatic pressure for a given change in tension, according to the law of LaPlace, inasmuch as the transdiaphragmatic pressure equals the product of the tension and a constant divided by the radius of curvature.

The infants studied tolerated their feedings and did not have cyanotic episodes associated with feedings. The increase in the diaphragmatic work after feeding was greater (in absolute terms) than the work performed on the lungs. It is not known how much diaphragmatic work may be necessary to cause muscular fatigue and apnea, although infants with the greatest diaphragmatic work have been observed to have clinically significant apnea (17). It is tempting to speculate that the increased diaphragmatic work imposed by gavage feeding of the small preterm infant, when compounded by abnormal pulmonary mechanics and an unstable chest wall, may be enough to cause diaphragmatic fatigue and apnea. Simultaneous measurements of these mechanical parameters of chest wall distortion and the frequency spectral content of the diaphragmatic electromyogram $(18,19)$ may help to define the threshold for diaphragmatic fatigue in the small preterm infant.

\section{REFERENCES}

1. Wilkinson A, Yu VYH 1974 Immediate effects of feeding on blood-gases and some cardiorespiratory functions in ill newborn infants. Lancet 6:1083-1085

2. Krauss AN, Brown JB, Waldman S, Gottlieb G, Auld PAM 1978 Pulmonary function following feeding in low-birth-weight infants. Am J Dis Child 132:139-142

3. Russel G, Feather EA 1970 Effects of feeding on respiratory mechanics of healthy newborn infants. Arch Dis Child 45:325-327

4. Bakulesh DP, Dinwiddie R, Kumar SP, Fox WW 1977 The effects of feeding on arterial blood gases and lung mechanics in newborn infants recovering from respiratory disease. J Pediatr 90:435-438

5. Feather E, Russell G 1974 Respiratory mechanics in infants of low birth weight and the effects of feeding. Biol Neonate 24:117-127

6. Pitcher-Wilmott R, Shutack JG, Fox WW 1979 Decreased lung volume after nasogastric feeding of neonates recovering from respiratory disease. $\mathrm{J}$ Pediatr 95:119-121

7. Heldt GP, McIlroy MB 1987 Distortion of chest wall and work of diaphragm in preterm infants. $\mathrm{J}$ Appl Physiol 62:164-169

8. Heldt GP, Mcllroy MB 1987 Dynamics of chest wall in preterm infants. J Appl Physiol 62:170-174

9. Duffty P, Spriet L, Bryan MH, Bryan AC 1981 Respiratory induction plethysmography (Respitrace): an evaluation of its use in the infant. Am Rev Respir Dis 123:542-546

10. Beardsmore CS, Helms P, Stocks J, Hatch DJ, Silverman M 1980 Improved esophageal balloon technique for use in infants. J Appl Physiol 149:735-742

11. Heldt PG, Targett RC, McIlroy MB 1982 A microcomputer-based data acquisition system for physiologic studies of the newborn. In: Harris TR, Bahr JP (eds) The Use of Computers in Perinatal Medicine. Praeger, New York, pp 353-362

12. Milner AD, Saunders RA, Hopkin IE 1978 Relationship of intra-esophageal pressure to mouth pressure during measurement of thoracic gas volume in the newborn. Biol Neonat 33:314-319

13. Krieger I 1980 Studies in mechanics of respiration in infancy. Am J Dis Child 105:51-60

14. Gerhardt T, Bancalari $E 1980$ Chest wall compliance in fullterm and preterm infants. Acta Paediatr Scand 69:359-364

15. Agostoni E 1959 Volume pressure relationship of thorax and lung in the newborn. J Appl Physiol 14:909-913

16. Barrie H 1968 Effect of feeding on gastric and oesphageal pressures in the newborn. Lancet 2:1158-1160

17. Heldt GP. Development of stability of the respiratory system of preterm infants. J Appl Physiol (in press)

18. Lynne-Davies P 1979 Diaphragmatic electromyographic studies: the application of frequency-domain and time-domain analysis. Am Rev Respir Dis 119:169-173

19. Muller N, Gulston G, Cade D, Whitton J, Froese AB, Bryan MH, Bryan AC 1979 Diaphragmatic muscle fatigue in the newborn. J Appl Physiol 46:688695 